\title{
MURCS association with absent hand and unusual vertebral anomaly
}

\author{
Mansoor C. Abdulla ${ }^{1 *}$, Saphina Palakkan², Jassim Mohamad Koya ${ }^{3}$, Krishnan Raman Menon ${ }^{1}$
}

\author{
${ }^{1}$ Department of General Medicine, M.E.S. Medical College, Perinthalmanna-679338, Kerala, India \\ ${ }^{2}$ Department of Obstetrics and Gynaecology, M.E.S. Medical College, Perinthalmanna-679338, Kerala, India \\ ${ }^{3}$ Department of Radiodiagnosis, M.E.S. Medical College, Perinthalmanna-679338, Kerala, India
}

Received: 10 April 2014

Accepted: 4 May 2014

\section{*Correspondence:}

Dr. Mansoor C. Abdulla,

E-mail: drcamans@gmail.com

(C) 2014 Abdulla MC et al. This is an open-access article distributed under the terms of the Creative Commons Attribution Non-Commercial License, which permits unrestricted non-commercial use, distribution, and reproduction in any medium, provided the original work is properly cited.

\begin{abstract}
Mullerian duct aplasia, Renal aplasia and Cervicothoracic Somite dysplasia (MURCS association) is a developmental field defect, diagnosed if both aplasia/hypoplasia of the Mullerian duct, renal agenesis/ectopy and anomalies of the cervicothoracic somites are present. We report a case of MURCS Association with the above features, absent hand, T12 Hemi vertebra and an exophytic bony outgrowth from C5 vertebra. An exophytic bony projection from the spinous process of C5 vertebra, presenting as a swelling over the neck has not been described previously as a skeletal malformation in MURCS Association. Absent hand as a skeletal malformation in MURCS association was not seen in the earlier literature. This case is reported since it adds to the wide spectrum of anomalies associated with MURCS association and helps in distinguishing MURCS association from the syndromes which may show overlap.
\end{abstract}

Keywords: MURCS association, Absent hand, Vertebral anomaly

\section{INTRODUCTION}

The Mayer-Rokitansky-Kuester-Hauser (MRKH) syndrome is characterized by congenital aplasia of the uterus and upper two thirds of the vagina in women with normal karyotype and secondary sexual characteristics.

The MRKH syndrome may occur alone or in association with other malformations. MURCS association includes Mullerrian duct aplasia, renal malformations and cervicothoracic somite dysplasia which are considered as a type of MRKH syndrome.

This case is reported since the two anomalies - absent hand and an exophytic bony projection from the spinous process of $\mathrm{C} 5$ vertebra, presenting as a swelling over the neck has not been described previously as a skeletal malformations in MURCS association.

\section{CASE REPORT}

A 40 year old unmarried female with primary amenorrhoea was admitted with history of lower abdominal pain of one week. She had been born the first child of a non-consanguineous marriage by vaginal delivery at term without complications. At birth, her weight was $2.3 \mathrm{~kg}$ ( $3^{\text {rd }}$ centile) and her length 0.5 meter $\left(50^{\text {th }}\right.$ centile). She was noticed to have absent left hand and a swelling over the neck region. Her developmental milestones had been normal. Her parents and four siblings were normal.

Her height was 1.56 meters $\left(50^{\text {th }}\right.$ centile), weight $37 \mathrm{~kg}$ $\left(5^{\text {th }}\right.$ centile), she had retrognathia, absent left hand (Figure 1), short neck and a smooth, hard, non-tender swelling over the neck. Her arm span was 1.58 meters, upper segment - lower segment ratio was 0.9. Genital examination showed a pair of labia majora and minora with urethral opening inside. There was no vaginal 
orifice; her secondary sexual characters were normally developed. The rest of the physical examination was unremarkable.

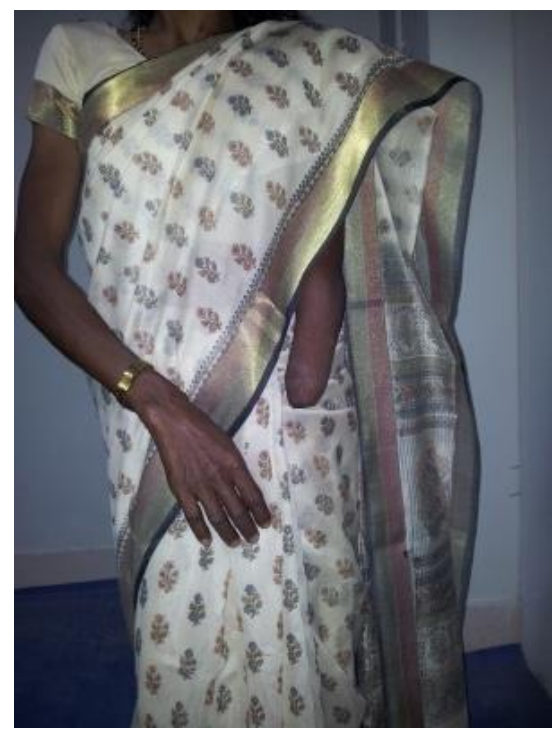

Figure 1: Absent left hand.

Investigations showed normal blood counts, renal, liver and thyroid functions. Urine microscopy revealed numerous pus cells. Ultrasonography showed absent uterus and right kidney. MRI confirmed the absence of uterus. She had rudimentary cervix and a midline isointense linear structure resembling the vagina (Figure 2 ). She also had T12 Hemi vertebra and crossed fused ectopia of kidneys on the left side (Figure 3). MRI of the cervical spine revealed C6-C7 block vertebra, with an exophytic bony projection from the spinous process of $\mathrm{C} 5$ vertebra (Figure 4). Echocardiogram was normal. Cytogenetic karyotyping showed a 46 XX karyotyping with the presence of Barr chromatin body.

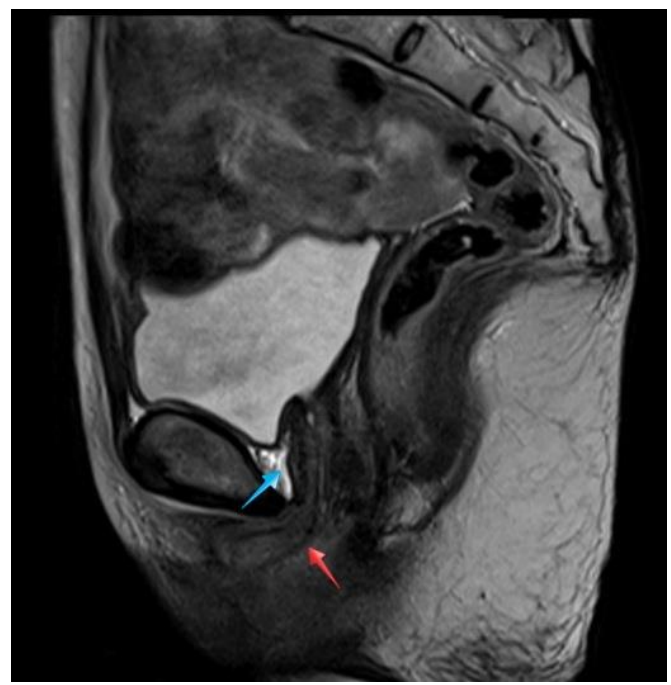

Figure 2: Sagittal T2 weighted image showing absent uterus, rudimentary cervix (blue arrow) and vagina (red arrow).

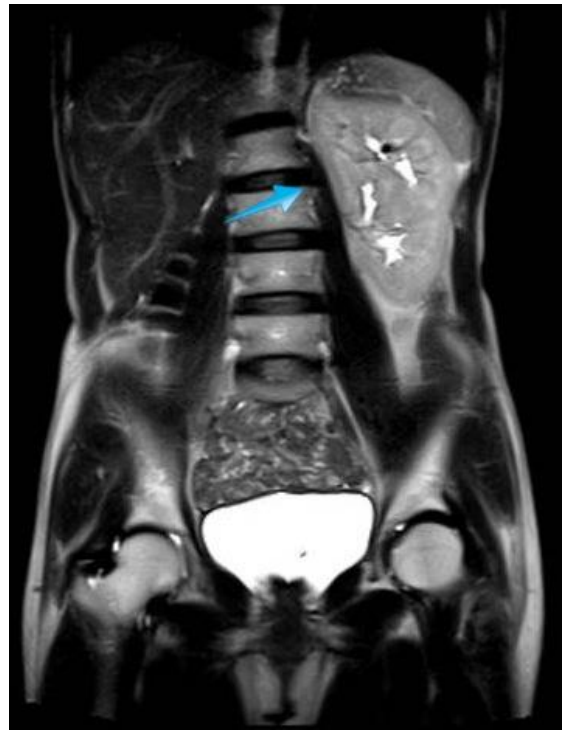

Figure 3: Coronal T2 Weighted image showing crossed fused ectopia of kidneys on the left.

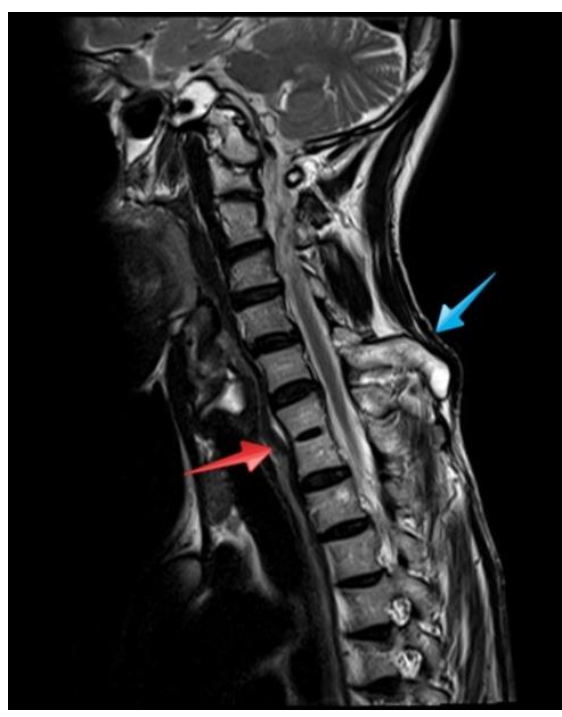

Figure 4: Sagittal T2 weighted image showing the partial block vertebrae C6-C7 (red arrow) and the osseous outgrowth from the spinous process of $\mathrm{C5}$ (blue arrow), abutting the overlying muscles and skin.

Based on the clinical examination and investigations a diagnosis of MURCS association was established with associated limb and skeletal deformities.

\section{DISCUSSION}

MURCS association is a developmental field defect and is diagnosed if both aplasia/hypoplasia of the Mullerian duct, renal agenesis/ectopy and anomalies of the cervicothoracic somites are present. ${ }^{1}$ It is attributed to an alteration of the blastema of the cervicothoracic somites and the pronephric ducts which, by the end of the fourth week of fetal life, have an ultimately spatial relationship. ${ }^{2}$ Upper urinary tract malformations are associated in about 
$40 \%$ of cases $^{3}$ - unilateral renal agenesis (23-28\%), ectopia of one or both kidneys (17\%), renal hypoplasia (4\%), horseshoe kidney and hydronephrosis. ${ }^{4}$ The skeletal malformations observed include vertebral abnormalities like spina bifida, sacralization of L5, lumbarization of the sacral bone (S1), and malformations of the cervical vertebrae. Similarly, anomalies of the extremities, particularly in the hands and fingers (syndactyly), rib deformities, cleft palate, shoulder blade and pelvic deformities, have also been reported. ${ }^{5}$

The renal (crossed fused ectopia of kidneys ${ }^{6}$ ) and vertebral segmentation defects (Cervical block vertebra and hemivertebra) described in our case have been reported earlier. But an exophytic bony projection from the spinous process of C5 vertebra, presenting as a swelling over the neck has not been described previously as a skeletal malformation in MURCS Association. Extremity malformations like ectrodactyly, duplicated thumb, ${ }^{7}$ absent radius, ${ }^{8}$ atrio-digital dysplasia (Holt-Oram like syndrome), ${ }^{9}$ thenar hypoplasia were reported along with MURCS association earlier. Absent hand as a skeletal malformation in MURCS association was not seen in the earlier literature.

This case is reported since it may add to the wide spectrum of anomalies associated with MURCS Association and help in distinguishing MURCS Association from the syndromes which may show overlap including syndromes with radial ray anomalies. ${ }^{10}$

Funding: No funding sources

Conflict of interest: None declared

Ethical approval: Not required

\section{REFERENCES}

1. Braun-Quentin C, Billes C, Bowing B, Kotzot D. MURCS association: case report and review. J Med Genet. 1996;33:618-20.

2. Duncan PA, Shapiro LR, Stangel JJ, Klein RM, Addonizio JC. The MURCS association: Mullerian duct aplasia, renal aplasia, and cervicothoracic somite dysplasia. J Pediatr. 1979,95:399-402.

3. Strubbe EH, Willemsen WN, Lemmens JA, Thijn CJ, Rolland R. Mayer-Rokitansky-Kuster-Hauser syndrome: distinction between two forms based on excretory urographic, sonographic, and laparoscopic findings. Am J Roentgenol. 1993;160:331-4.

4. Pittock ST, Babovic-Vuksanovic D, Lteif A. MayerRokitansky-Kuster-Hauser anomaly and its associated malformations. Am J Med Genet A. 2005;135:314-6.

5. Oppelt P, Renner SP, Kellermann A, Brucker S, Hauser GA, Ludwig KS et al. Clinical aspects of Mayer-Rokitansky-Kuester-Hauser syndrome: recommendations for clinical diagnosis and staging. Hum Reprod. 2006;21:792-7.

6. Dasgupta, Shyamal et al. Mayer-Rokitansky-KusterHauser type-B anomaly with MURCS association and gonadal dysgenesis. J Obstet Gynaecol India. 2012;62(Suppl 1):83-4.

7. Lopez AG, Fryns JP, Devriendt K. MURCS association with duplicated thumb. Clin Genet. 2002;61:308-9.

8. Behera M, Couchman G, Walmer D, Price TM. Mullerian agenesis and thrombocytopenia absent radius syndrome: a case report and review of syndromes associated with Mullerian agenesis. Obstet Gynecol Surv. 2005;60:453-61.

9. Ulrich U, Schrickel J, Dorn C, Richter O, Lewalter $\mathrm{T}$, Luderitz B et al. Mayer-von-Rokitansky-KusterHauser syndrome in association with a hitherto undescribed variant of the Holt-Oram syndrome with an aorto-pulmonary window. Hum Reprod. 2004;19:1201-3.

10. Gardner RJ. McKinlay, Mark P. Umstad, Lyndon G. Hale. MURCS and thenar hypoplasia. Clin Dysmorphol. 2007;16(4):275-6.

DOI: $10.5455 / 2320-1770$. ijrcog20140641

Cite this article as: Abdulla MC, Palakkan S, Koya JM, Menon KR. MURCS association with absent hand and unusual vertebral anomaly. Int J Reprod Contracept Obstet Gynecol 2014;3:472-4. 